\title{
Editorial
}

\section{Mais um Recomeço}

De forma mais ampla, parece que a modernidade ocidental só poderá expandir-se globalmente na medida em que viole todos os princípios sobre os quais fez assentar a legitimidade histórica do paradigma da regulação/emancipação deste lado da linha. Direitos humanos são desta forma violados para poderem ser defendidos, a democracia é destruída para garantir a sua salvaguarda, a vida é eliminada em nome da sua preservação. Linhas abissais são traçadas tanto no sentido literal como metafórico.

Boaventura de Souza Santos (2007, pp. 14-15)

Começamos um novo ano e, com ele, um novo volume da revista Psicologia: Teoria e Pesquisa. Como todo recomeço, este que inaugura o volume 24 vem acompanhado de muitas promessas e grandes expectativas. $\mathrm{O}$ ano passado foi muito profícuo para a revista Psicologia: Teoria e Pesquisa: além de honrar o compromisso de aumentar sua periodicidade de quadrimestral para trimestral, foi possível lançar um número especial em homenagem aos Professores de renovado prestígio no campo da Psicologia, que foram laureados com títulos de Professores Eméritos e Doutor Honoris Causa pela Universidade de Brasília. Portanto, foram cinco os exemplares lançados pela revista no ano passado. $\mathrm{O}$ apoio significativo dos órgãos de fomento - CNPq e CAPES -, e da própria instituição, foram cruciais para o êxito dos empreendimentos de 2007.

No entanto, como já prenuncia o grande sociólogo da pós-modernidade Boaventura de Souza Santos, enquanto aguardamos a emergência do pensamento pós-abissal, mergulhamos na árdua e contínua tarefa de administrar e recriar as condições para seguir divulgando a produção do conhecimento científico na área da psicologia. Dessa forma, este ano, ainda que com parcos recursos, pretendemos continuar publicando trimestralmente as contribuições de alta qualidade e rigor de autores da comunidade científica nacional e internacional.

Nesse sentido e para selar nosso compromisso, neste primeiro número de 2008, oferecemos aos leitores dois excelentes artigos de autores estrangeiros: Nathalie Dumet, em seu artigo em língua francesa, discute a hipótese de que a perturbação psicossomática constitui um vestígio traumático de uma experiência passada na espera de subjetivação, apresentando e discutindo três casos clínicos. Mario Aletti, por seu turno, discute com formidável clareza, a questão das semelhanças e diferenças entre a psicoterapia e o aconselhamento espiritual em um artigo gentilmente traduzido por Geraldo Paiva.

As contribuições nacionais também são de altíssimo nível: Luísa Habigzang, Roberta Hatzenberger, Fabiana Corte, Fernanda Stroeher e Sílvia Koller avaliam a efetividade de um modelo de grupoterapia cognitivo-comportamental para meninas vítimas de abuso sexual. Eunice Soriano e Denise
Fleith investigam a percepção de professores do ensino fundamental sobre barreiras que os dificultam propiciar condições favoráveis ao desenvolvimento da capacidade criativa de seus alunos. Fernando Orphão de Carvalho propõe uma breve revisão do conceito de seleção sexual e do seu uso e status na psicologia evolucionista.

$\mathrm{Na}$ área do desenvolvimento infantil e da interação família-bebê, o presente número contempla uma diversidade de temáticas: Gimol Perosa, Flávia Pereira Silveira e Isabela Canavez avaliam as condições emocionais de mães de recém-nascidos nascem com malformações visíveis. Já Célia Nunes, Nancy da Silva e Ana Lúcia Aiello revêm a literatura sobre as principais contribuições do pai e do irmão do indivíduo com necessidades especiais tendo como base a visão sistêmica da família. Maria Lyra e Antonio Roazzi comparam duas abordagens teórico-metodológicas distintas e investigam a concepção que mães apresentam acerca do processo de desenvolvimento da comunicação mãe-bebê. Thais de Oliveira e Maria Stella Gil descrevem o desempenho de bebês em relação a tarefas de discriminação, reversão e remediativos em condições experimentais.

$\mathrm{Na}$ área de psicologia da aprendizagem, Elenice Hanna, Marina Kohlsdorf, Regiane Quinteiro e Virgínia Fava relatam o emprego de um sistema lingüístico em miniatura para investigar a aprendizagem de leitura em estudantes universitários. Na perspectiva epistemológica, Elizeu Borloti, Alexandra Iglesias, Camila Dalvi e Renata Silva discutem a tese de que a análise comportamental do discurso é uma vertente de análise do discurso, devido aos seus fundamentos epistemológicos: anti-mentalismo, anti-realismo e contextualismo.

$\mathrm{Na}$ área da psicologia cognitiva, Michelle Levitan, Bernard Rangé e Antonio Nardi fazem uma revisão de literatura em bases de dados bibliométricas acerca da associação entre os transtornos ansiosos e o déficit de habilidades sociais. $\mathrm{Na}$ área da psicologia clínica, Maria Leonor Enéas faz um levantamento sobre as pesquisas em psicoterapia publicados no periódico da American Psychological Association e pretende oferecer uma visão qualitativa do desenvolvimento e das tendências da área.

Por último, apresenta-se uma notícia - sobre o Congreso Latinoamericano de Psicología de la Salud e XI Encontro Nacional de Psicólogos da Ârea Hospitalar, ocorrida de 15 a 18 de novembro em São Paulo - elaborada por Roberto Menezes Alessandra Arrais e Tereza Cristina Araújo.

Espero que desfrutem da leitura deste!

\section{Referência}

Santos, B. S. (2007). Para além do Pensamento Abissal: Das linhas globais a uma ecologia de saberes. Revista Crítica de Ciências Sociais, 78, 3-48. 